\title{
Microstructural aspects of laser surface treatment of commercially pure titanium
}

\author{
J. Iwaszko* \\ Czestochowa University of Technology, Institute of Materials Engineering, \\ 19 Armii Krajowej St., 42-200 Czestochowa, Poland
}

Received 30 May 2018, received in revised form 23 October 2018, accepted 25 October 2018

\begin{abstract}
Commercially pure $(\mathrm{CP})$ titanium was subjected to $\mathrm{cw}-\mathrm{CO}_{2}$ laser surface treatment. The treatment was carried out using a side-by-side dual laser beam. The initial and surface treated materials were subjected to structural and microstructural examination. It was found that the microstructure in the laser treated zone changed from an $\alpha$-phase present in the non-remelted material to martensite $\alpha^{\prime}$ as a consequence of the very high rates of cooling. An increase in the diffraction reflections originating from the (101) titanium plane was observed in the remelted sample. Despite the fact the laser treatment was conducted in a protective gas shield, limited oxidation occurring due to the high reactivity of titanium was observed. Analysis of the remelting parameters in connection with the macroscopic evaluation and microstructural changes in the surface layer allowed the relationships facilitating the shaping of the melting zone geometry, as well as the scope of microstructural changes to be determined.
\end{abstract}

K e y word s: CP titanium, laser treatment, microstructure characterization

\section{Introduction}

Titanium and its alloys have unique mechanical and physicochemical properties that make them useful in the wide range of applications in modern technology, aeronautics, and the automotive industry. Titanium is a light metal whose specific gravity is $4.54 \mathrm{~g} \mathrm{~cm}^{-3}$. Pure titanium melts at $1670^{\circ} \mathrm{C}$. The strength of titanium can be compared to that of steel with its density amounting to merely $60 \%$ of that of steel [1]. Titanium is resistant to salt, polluted water, and corrosion in both acidic and alkaline environments. The strength properties of titanium strongly depend on its purity. Because of that, the admixtures of other elements such as oxygen, nitrogen, and carbon considerably change its properties. Titanium is highly reactive; heating it in air leads to the creation of oxides and nitrides on its surface. Despite the exceptional properties of titanium that make it one of the most promising and innovative metal materials, its application is limited due to its low hardness and poor tribological properties such as poor abrasive wear resistance and high coefficient of friction. To improve its mechanical properties, the titanium surface is often modified. The surface modification technologies include mechanical or thermal treatments, thermal spraying, sol-gel, chemical and electrochemical treatment, ion implantation, and surface alloying [1-5]. Increasingly more frequently titanium and its alloys are subjected to laser surface treatment. The laser modification is generally carried out using Nd:YAG lasers $[6,7]$ or $\mathrm{CO}_{2}$ lasers $[8,9]$. Laser surface treatment is one of the most innovative and effective methods of surface treatment of a wide range of engineering materials [10-15]. The application of a laser beam causes the microstructure of the treated material to be formed in the conditions of a high-temperature gradient and a very short process duration. Such induced changes may lead to obtaining a material having properties that cannot be achieved with classical heat or thermo-chemical treatment methods. Another advantage of laser surface treatment over conventional heat treatment is its capability to localize treatment on a selected part of a surface, leaving the other parts unaffected [10]. In the case of pure titanium or titanium alloys, studies have focused on the microstruc-

*Corresponding author: e-mail address: iwaszko@wip.pcz.pl 
Table 1. Titanium remelting process parameters

\begin{tabular}{ccccc}
\hline No. & $\begin{array}{c}\text { Laser power, } P \\
(\mathrm{~W})\end{array}$ & $\begin{array}{c}\text { Scan rate, } V_{\mathrm{p}} \\
\left(\mathrm{m} \mathrm{min}^{-1}\right)\end{array}$ & $\begin{array}{c}\text { Argon blow-in rate } \\
\text { in the side nozzle } \\
\left(\mathrm{dm}^{3} \mathrm{~min}^{-1}\right)\end{array}$ & $\begin{array}{c}\text { Helium blow-in rate } \\
\text { in the central nozzle } \\
\left(\mathrm{dm}^{3} \mathrm{~min}^{-1}\right)\end{array}$ \\
\hline 1 & 500 & 0.50 & 20 & 12 \\
2 & 500 & 0.35 & 20 & 12 \\
3 & 500 & 0.20 & 20 & 12 \\
4 & 500 & 0.10 & 20 & 12 \\
5 & 1000 & 0.50 & 20 & 12 \\
7 & 1000 & 0.35 & 20 & 12 \\
8 & 1500 & 0.20 & 20 & 12 \\
\hline
\end{tabular}

tural and technological aspects of surface remelting and changes in the properties of the modified material. For example, Sun et al. [16] investigated the effect of Nd-YAG laser surface remelting on the corrosion resistance of pure titanium. The results showed that the pitting corrosion resistance and pitting potential of a titanium remelted surface increased significantly in comparison with the non-remelted material. This improvement was attributed to microstructural changes caused by the rapid solidification that occurs during laser surface remelting. In turn, in work [17], the effects of the shielding gas flow rate on the nitrogen and oxygen concentrations and Vickers hardness of YAG laser melted pure titanium were investigated. It was found that the remelted region has a uniform dislocation structure consisting of mostly $\beta$-Ti and a very small amount of $\alpha$-Ti. It was also found that when the shielding gas flow rate decreased, the oxygen and nitrogen concentrations of the laser melted zone and the average hardness also increased. Ciganovic et al. [9] analysed the interaction of a nanosecond TEA $\mathrm{CO}_{2}$ laser with a titanium implant surface in various gas atmospheres, and they found that the reported laser fluence and gas ambiences can effectively be applied to enhance the titanium implant roughness and create titanium oxides and nitrides on a strictly localized surface area. In turn, the main aim of work [18] was to investigate the effect of laser surface treatment on the mechanical properties of cast titanium and to compare them with those of the $\mathrm{Co}-\mathrm{Cr}$ alloy. The cast titanium specimen surfaces were laser-treated using a dental Nd:YAG laser machine. It was found that laser treatments of cast titanium decreased the brittle subsurface hardness induced by titanium casting and significantly improved the mechanical properties of cast titanium by improving the surface integrity of the cast surface contamination. In work [7] PoulonQuintin et al. investigated the effect of Nd:YAG laser surface treatment of cast titanium on the microstructure and mechanical properties and they found significant enhancement of the mechanical properties, while a higher tensile strength and higher values of elastic modulus of titanium were also obtained. Can Huang et al. [19] analysed the microstructural evolution of pure titanium treated by a Nd:YAG laser under different processing parameters and observed three distinctly different types of microstructure from the surface to the substrate in Ti samples, namely phase transformation and solidification microstructure in the melting zone, insufficient grain recrystallization with residual martensitic plates in the heat-affected zone, and a fully recrystallized microstructure in the base metal. The authors showed that the material in the melting zone had the highest hardness, while the material in the heat affected zone had the lowest hardness value due to the insufficiently recrystallized grains.

In this study, surface remelting treatment of pure titanium was carried out using a cw- $\mathrm{CO}_{2}$ side-by-side dual laser beam. The structure and microstructure of the remelted surface layer were analysed and discussed.

\section{Material and experimental procedure}

Commercially pure titanium flat plates with the dimensions $55 \mathrm{~mm} \times 30 \mathrm{~mm} \times 10 \mathrm{~mm}$ were used in the experiment. The purity of the titanium was $99.6 \%$ (ASTM Grade 2). The plates were mechanically polished, and afterwards, the surfaces of the samples were chemically cleaned with acetone before treatment to eliminate surface contamination. The laser surface treatment was carried out using a Trumpf Lasercell laser machine equipped with a TLF $3.8 \mathrm{~kW} \mathrm{CO}$ gas laser with continuous operating characteristics. The titanium surface was treated with a laser power ranging from 500 to $1500 \mathrm{~W}$ and a scan rate ranging from 0.1 to $0.5 \mathrm{~m} \mathrm{~min}^{-1}$. The parameters of the surface treatment are given in Table 1. In the laser treatment of the titanium surface layer, a double beam focusing technique was used to obtain two laser beams focused on two different points of the melted material. The laser beam splitting effect was obtained using a special mirror. Mutual alignment of the beams, the abil- 

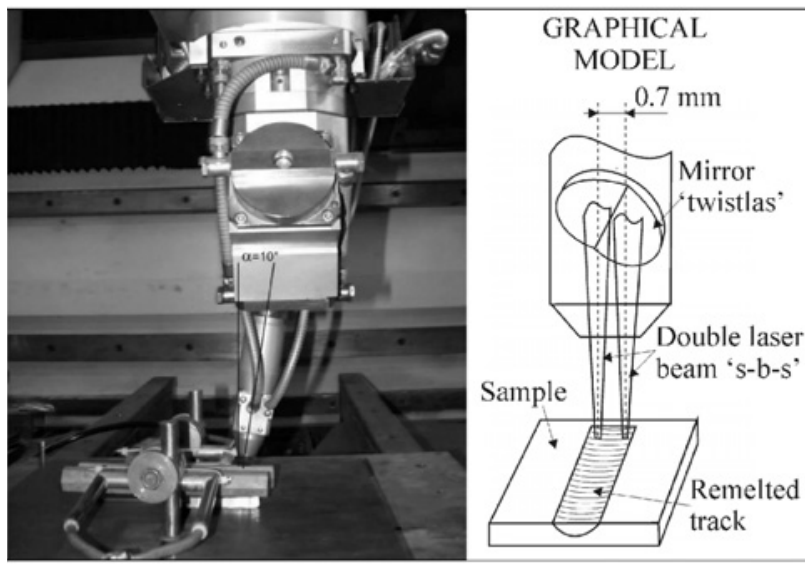

Fig. 1. Dual laser beam titanium remelting process.

ity to change the distance between the foci and the power of individual beams allowed greater control of both the geometry of the remelting zone and the nature and extent of microstructural changes induced in the melted material. A Twistlas bifocal mirror with the focal length of $270 \mathrm{~mm}$ was used in the experiment. The mirror enables one to obtain two laser beams focused on two different points of the metal being remelted. The treatment was conducted with a dual laser beam in the s-b-s (side-by-side) configuration. The distance between the adjacent beams was $0.7 \mathrm{~mm}$. The titanium remelting process and geometry of the dual laser beam are illustrated in Fig. 1. Argon was used as a shielding gas, and the blow-in rate was $20 \mathrm{dm}^{3} \mathrm{~min}^{-1}$ from the side nozzles. Helium was supplied by the central nozzle, and the blow-in rate was $12 \mathrm{dm}^{3} \mathrm{~min}^{-1}$. Titanium shows high chemical affinity at higher temperatures, especially to oxygen and nitrogen and that is why it was necessary to use the shielding gas. The argon blast was also maintained after completing the remelting to safeguard the liquid pool and cooling material against the interaction of the ambient atmosphere. In the case of titanium and its alloys, the oxidability decreases only below $650^{\circ} \mathrm{C}$. The track dimensions and the effects of laser processing on the titanium plate microstructure were regulated by both the scanning rate and laser power. Exemplary macroscopic effects of remelting are shown in Fig. 2.

Metallographic samples were prepared by a standard metallographic procedure. The specimens were cut transversely to the laser track. Next, the track cross-section specimens were ground and polished with a diamond paste. Then the polished specimens were chemically etched in a solution of $\mathrm{HNO}_{3}$ and $\mathrm{HF}$ in $\mathrm{H}_{2} \mathrm{O}$.

The EDS method was used to evaluate the chemical composition of selected micro-areas in the titanium samples. The remelted surface, the core of the
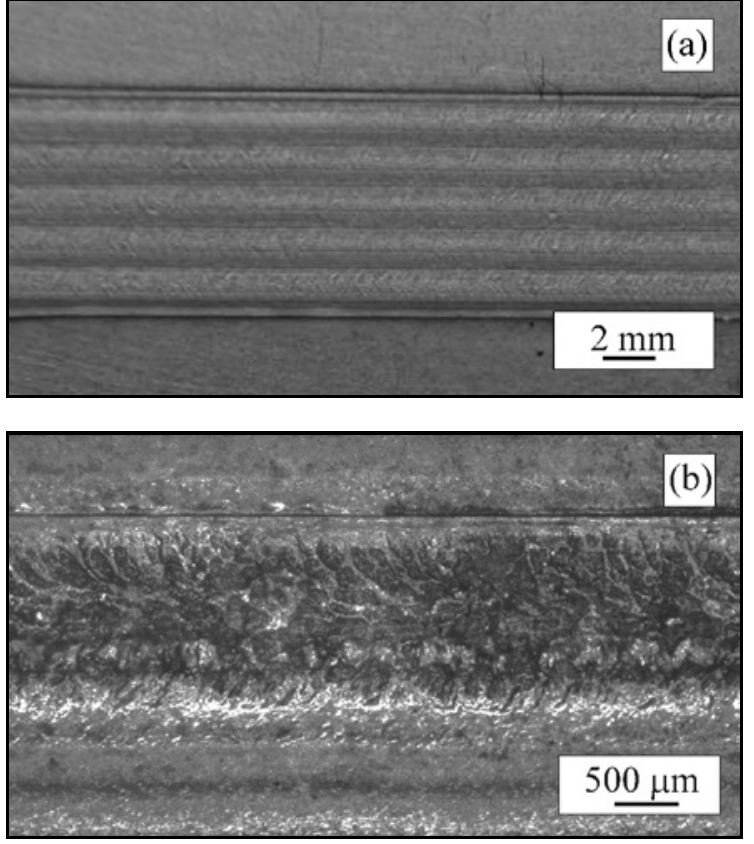

Fig. 2. Titanium surface after laser processing using sideby-side dual laser beam; treatment parameters: $V_{\mathrm{p}}=$ $0.5 \mathrm{~m} \mathrm{~min}^{-1}, P=1500 \mathrm{~W}$.

material as well as micro-areas located in three places within the remelted zone at different distances from the surface, i.e. in the subsurface zone, in the central part and the lower part of the penetration zone were subjected to analysis.

The microstructure was investigated by light microscopy (Olympus GX41) and scanning electron microscopy (JEOL JSM-6610LV). The phase composition of the samples was determined by X-ray diffraction with a Seifert XRD-3003 diffractometer (Rich. Seifert \& Co, Hamburg) using filtered $\mathrm{CoK} \alpha$ radiation $(\lambda=0.17902 \mathrm{~nm})$ operated at $30 \mathrm{kV}$ and $40 \mathrm{~mA}$. The used exposure time was $186 \mathrm{~min}$, and the analysed spectra were taken from the $2 \theta$ range of $20^{\circ}-90^{\circ}$.

\section{Results and discussion}

\subsection{Effect of laser processing parameters on remelted zone dimensions}

The carried out micro- and macrostructural studies showed that controlling the treatment parameters enables shaping of the material remelting zone geometry arbitrarily. The dimensions of the remelting zone were the result of the applied remelting parameters; an increase in laser power or reduction in the scan rate resulted in a dimensional increase in the remelting zone. Figure 3 presents exemplary relationships between the remelting parameters and dimensions of the remelted zone. 

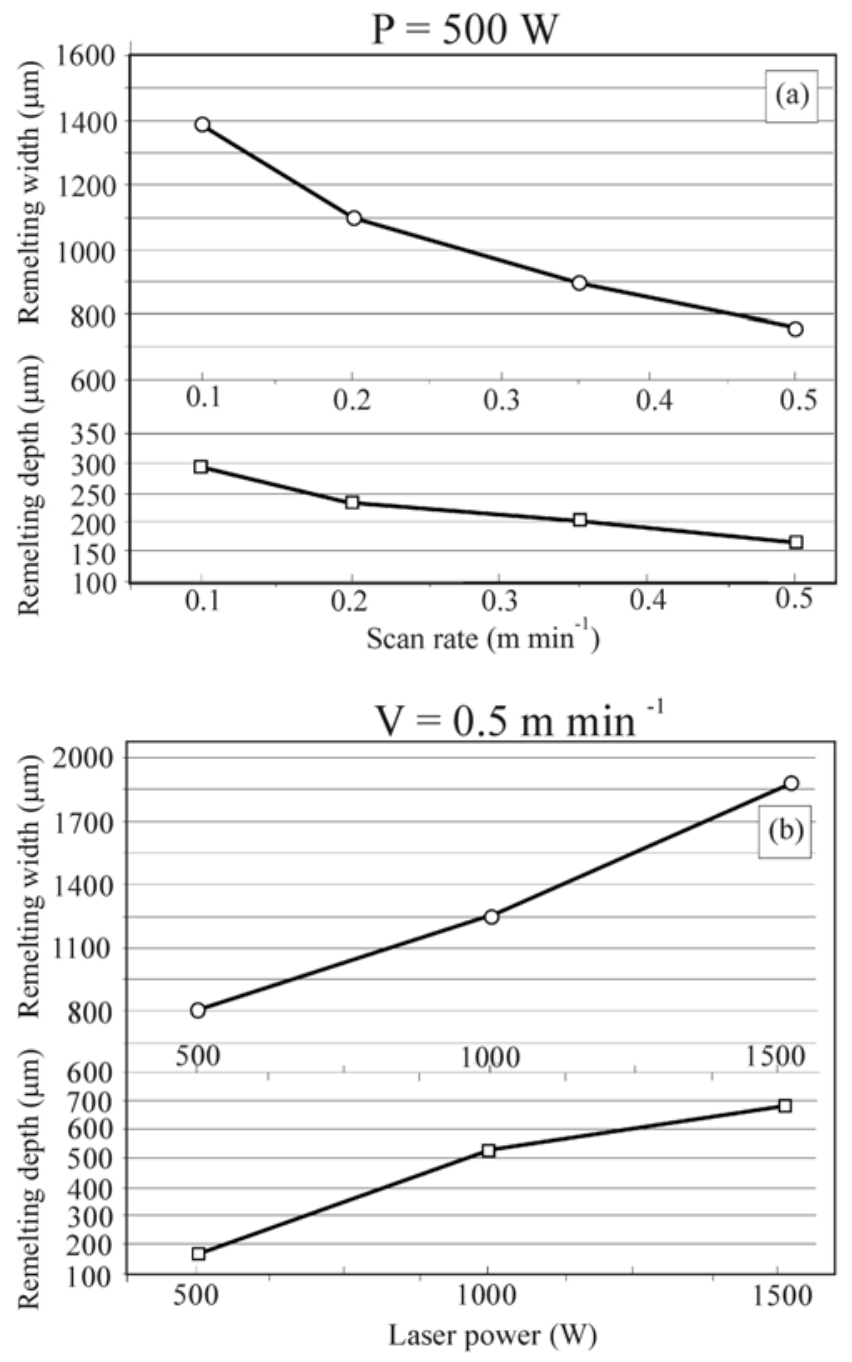

Fig. 3. The relation between remelted zone dimensions and scan rate (a), and laser power (b).

Within the adopted treatment parameters, the obtained remelting depth was of the order of $0.2-0.7 \mathrm{~mm}$. The width of the remelting zone was in the range of $0.7-1.9 \mathrm{~mm}$. The largest dimensions for both the depth and width of the remelting zone were recorded for the band remelted at the scan rate $V_{\mathrm{p}}=0.2 \mathrm{~m} \mathrm{~min}^{-1}$ and laser power $P=1500 \mathrm{~W}$. In this case, the remelting depth amounted to $0.7 \mathrm{~mm}$. The smallest depth amounting to almost $0.2 \mathrm{~mm}$ was noted for the power of $500 \mathrm{~W}$ and a scan rate of $0.5 \mathrm{~m} \mathrm{~min}^{-1}$. The analysis showed that doubling the laser speed made the remelting zone width smaller by about $25 \%$ and its depth reduced by about $30 \%$. In turn, doubling the laser beam power results in an increase in the bandwidth by about $50 \%$, and depth by almost $260 \%$. The tests showed high dimensional repeatability of the remelting results obtained after an s-b-s dual beam was used.

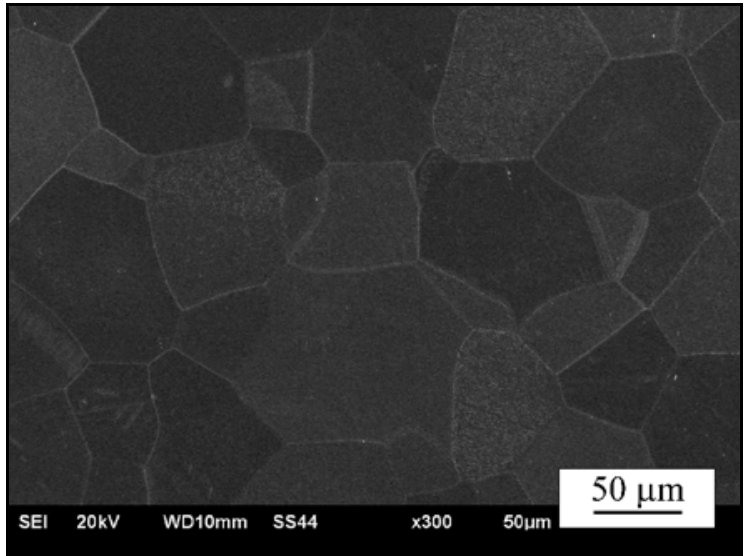

Fig. 4. The microstructure of untreated specimen, light microscope, cross-section, etched.

\subsection{Macro- and microstructure}

The titanium samples were examined before and after laser treatment. The investigations using both light microscopy and electron scanning microscopy revealed a single-phase microstructure typical for titanium with equiaxed, recrystallized grains of alpha titanium. The average size of $\alpha$-Ti grains was about $60 \mu \mathrm{m}$. This microstructure is shown in Fig. 4. The non-remelted material was homogeneous, without any microstructural defects.

Within the adopted remelting parameters no adverse changes (e.g. loss of material, loss band continuity, etc.) in the surface geometry were found. The observed changes were typical of samples remelted with lasers or other highly concentrated heat sources. Among some particularly characteristic features observed in the first phase of the microstructural tests were the effects of the crystallization arranged radially from the path axis towards the remelting borderline. This arrangement corresponded to the displacement of the crystallization front. The surface morphologies of the laser-treated titanium samples are shown in Fig. 5.

The structure fracture analysis did not reveal any presence of structural defects such as microcracks or delamination on the remelted interface. However, a small number of gas bubbles in the subsurface layer was found. Characteristic gas bubble cavities can also be observed on the band surface (Fig. 5a). The morphology of titanium observed in the central part of the remelted pass is shown in Fig. 5b.

Ultra-fast cooling normally leads to substantial changes in the microstructure, manifesting strong refinement of the microstructure and alternation of the morphology of the initial phases. The microscopic investigation of titanium after laser treatment revealed considerable changes in the titanium microstructure in relation to its state before the treatment. Figure 6 

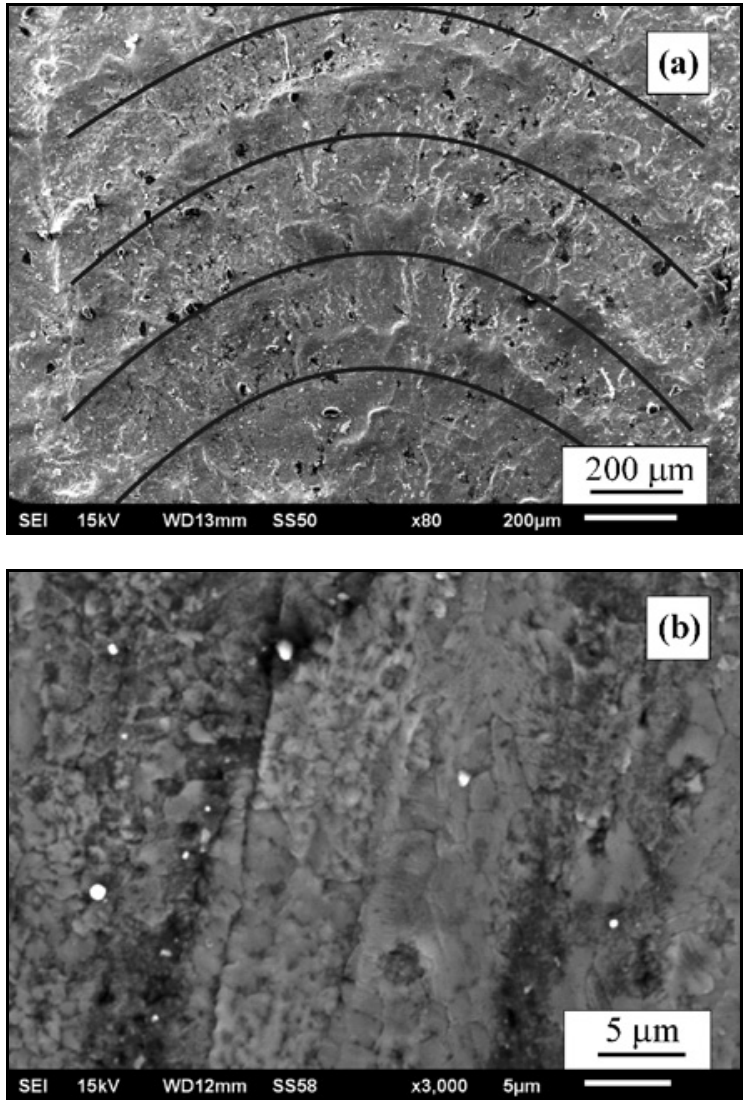

Fig. 5. SEM images showing typical surface morphologies of laser processed Ti samples; treatment parameters: $P=$ $1000 \mathrm{~W}, V_{\mathrm{p}}=0.5 \mathrm{~m} \mathrm{~min}^{-1}$; gas bubble cavities on the band surface (a), the morphology of $\mathrm{Ti}$ in the central part of the remelted pass (b).

shows an example of a single-track cross-section of the laser-treated zone. In the surface layer, the presence of a fine $\alpha^{\prime}$ martensite microstructure was found. Martensite is a nonequilibrium supersaturated alphatype structure produced by diffusionless (martensitic) transformation of the beta [20]. The $\alpha^{\prime}$ form has a hexagonal crystal structure and can be formed only by quenching [20]. It is worth adding that the $\alpha^{\prime}$ martensite possesses high hardness, but relatively low ductility and toughness. The martensitic microstructure was observed in all the analysed samples.

Regarding the laser processing parameters used, no significant differences were found in the morphology or degree of refinement of the martensitic phase. The morphology and degree of martensite refinement depend on the material cooling rate [21]. The lathtype martensite is reported to occur for cooling rates above $10^{3} \mathrm{~K} \mathrm{~s}^{-1}$ [22], while even higher rates of cooling $\left(10^{5}-10^{6} \mathrm{~K} \mathrm{~s}^{-1}\right)$ may produce a finer lath-type $\alpha^{\prime}$ martensite or a fine acicular martensitic morphology [23]. In all the analysed samples the acicular martensitic phase was dominant.
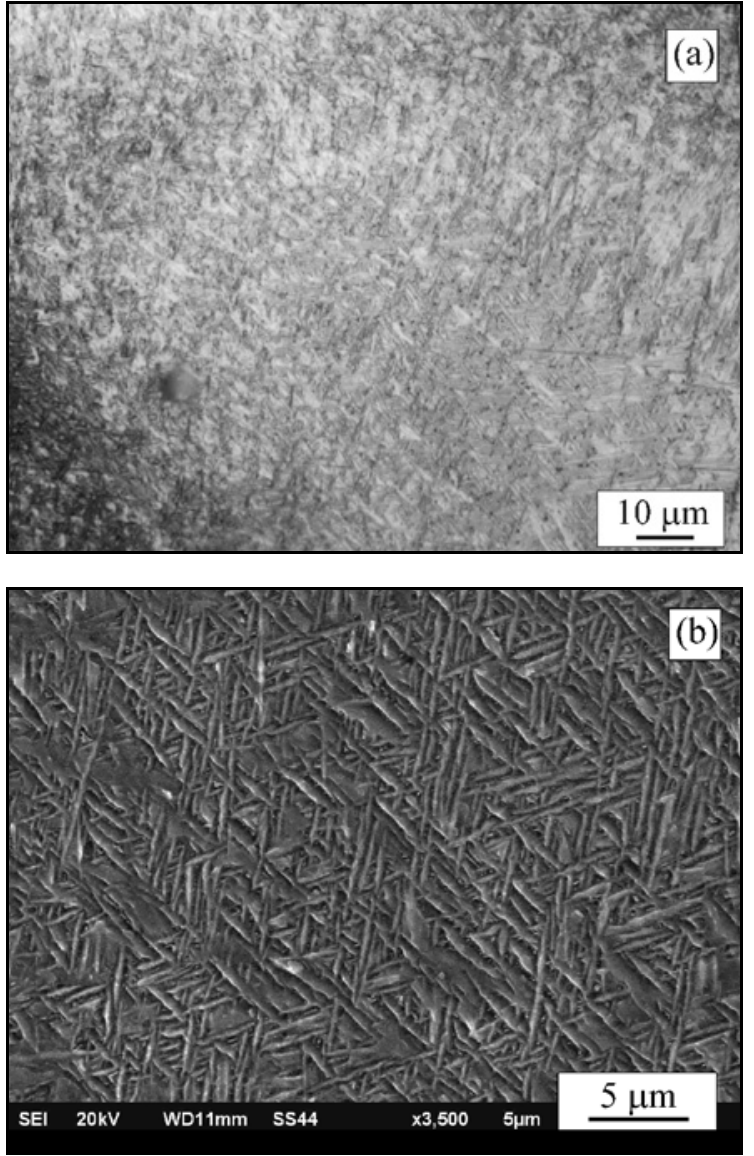

Fig. 6. Microstructures of CP-Ti after laser surface treatment at a laser power of $500 \mathrm{~W}$ and a scan rate of $0.35 \mathrm{~m} \mathrm{~min}^{-1}$, light microscopy (a), SEM (b).

It is worth noting that no pores or microcracks were seen at the interface between the remelted layer and the substrate, but some open pores were observed on the surface.

The nature of material fracture constitutes one of the criteria of the initial quality assessment of the material, its homogeneity and purity, susceptibility to cracking/breaking, mechanical properties, etc. This is why it was decided to carry out fractographic investigations. These investigations were conducted on the samples after being laser treated, and the SEM analysis included both the remelted part and remelted core of the material. As expected, the investigation of the fracture of the remelted area revealed a clearly different morphology when compared to the fracture in the non-remelted part. In the remelted part, the dominating feature of cleavage fracture with the poorly developed surface geometry, characteristic for this type of fracture was found (Fig. 7).

Along with an increasing distance from the remelted surface, an increasing proportion of the morphology of ductile fracture type, or mixed fracture but with 

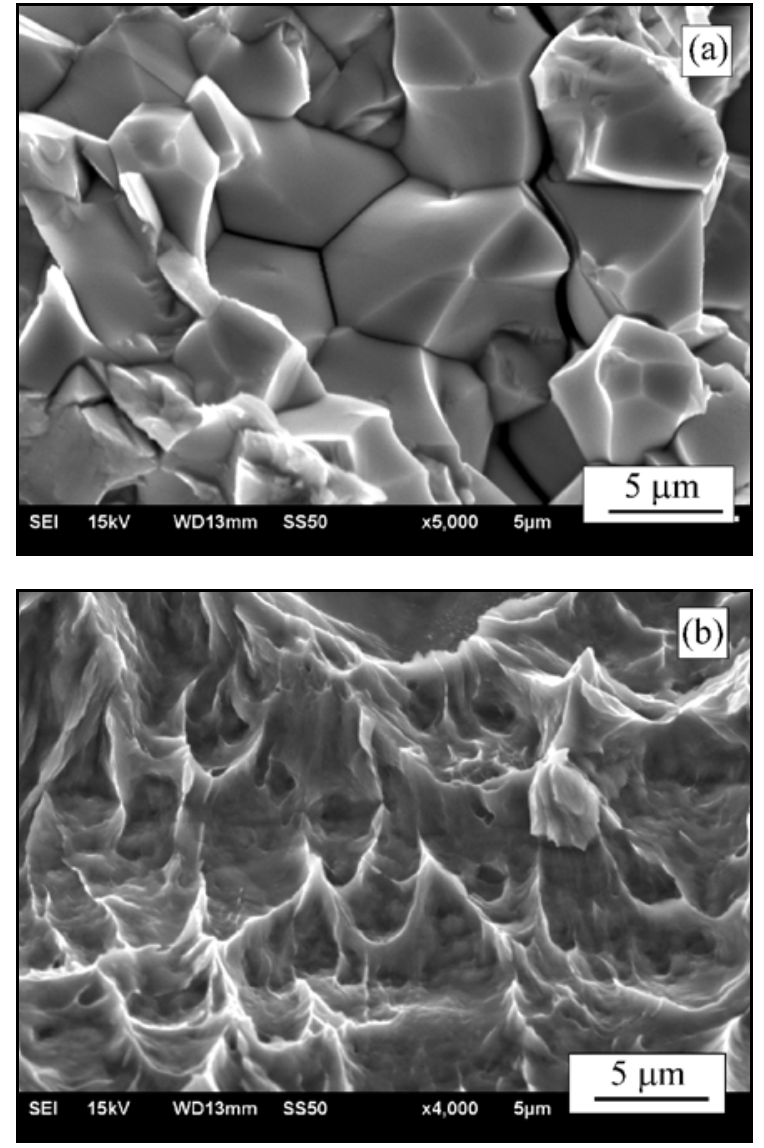

Fig. 7. Microstructure of fracture in remelted (a) and untreated (b) zones; treatment parameters: $P=1000 \mathrm{~W}$, $V_{\mathrm{p}}=0.5 \mathrm{~m} \mathrm{~min}^{-1}$.

the predominance of the elements of ductile fracture morphology was observed. The increasing proportion of the ductile fracture, along with an increasing distance from the surface, is a natural consequence of the reduced cooling of the material. The well-developed surface with numerous cavities and convexities created during the plastic strain of the material constituted the special structural effects observed in the non-remelted part.

\subsection{Phase composition}

Pure titanium is polymorphic, above $882^{\circ} \mathrm{C}$ the titanium occurs in the form of a body-centred cubic (bcc) $\beta$-phase, while below $882^{\circ} \mathrm{C}$ a hexagonally closepacked (hcp) $\alpha$-phase with a $c / a$ ratio of 1.587 occurs. At $882^{\circ} \mathrm{C} \mathrm{hcp} \alpha$-titanium undergoes an allotropic transformation to a bcc $\beta$-phase which remains stable to the melting temperature, i.e. $1670^{\circ} \mathrm{C}$. The $\beta$ $\rightarrow \alpha$ transformation is reversible. Under conditions of extremely high cooling both qualitative and quantitative changes in the structure of each material are taking place. As a consequence, some non-equilibrium phases and structures may come into being, and theoretically, even diffusion-nucleation processes may be blocked which ends with the material becoming amorphous. Thus, in the case of non-equilibrium cooling conditions, a $\beta \rightarrow \alpha^{\prime}$ martensitic transformation may occur in the case of titanium. The phase composition tests performed on the non-treated titanium revealed the presence of clear peaks from the $\alpha$-Ti hcp crystalline phase with (002) and (101) orientation typical for this phase prevailing. The titanium diffraction peaks corresponded with hexagonal close-packed (hcp) Ti (JCPDS Card No. 89-3725). In the case of the material subjected to surface remelting treatment, a slight shift in reflections from the crystallographic planes of titanium to higher values of the diffraction angle was found, which proves the presence of the h.c.p. $\alpha^{\prime}$ martensitic phase in the analysed material resulting from the $\beta \rightarrow \alpha^{\prime}$ phase transformation and caused by extremely high cooling of the material. A similar effect was observed, among others, in [24]. What is more, in the laser-treated titanium the presence of diffraction reflections originating from the $\mathrm{TiO}_{2}$ oxide phases was revealed. The presence of the oxide phase indicates that contrary to the initial assessments made in the microscopic investigations, the gas protection applied during the process of laser treatment was not sufficiently effective, and it needs to be improved in subsequent tests. No diffraction reflections originating from titanium nitride were observed in the tested samples. A comparative analysis of the diffraction records for the laser-treated samples and their equivalents but without any treatment allowed us to observe an abnormal enhancement of the reflections from certain lattice planes in the remelted samples. Particularly, a clear increase in the diffraction reflections originating from the crystallographic plane (101) was observed. The laser surface treatment makes the material structure and microstructure to be shaped under extremely non-equilibrium conditions. As a consequence of this, the changes in the primary crystallographic orientation of the material can be observed. The diffraction patterns of titanium before and after laser treatment are presented in Fig. 8.

\subsection{EDS analysis}

The main goal of the EDS research was to determine the variability of the chemical composition as a function of the distance from the surface of the sample and to determine the chemical composition of the surface of the remelted band. Titanium is a highly reactive element. Despite the use of a gas shield during processing, it was possible for oxygen or nitrogen from the atmosphere to get into the remelted material. The EDS analysis was also aimed at assessing the effectiveness of the gas shield used in the treatment. The EDS studies of the samples subjected to 


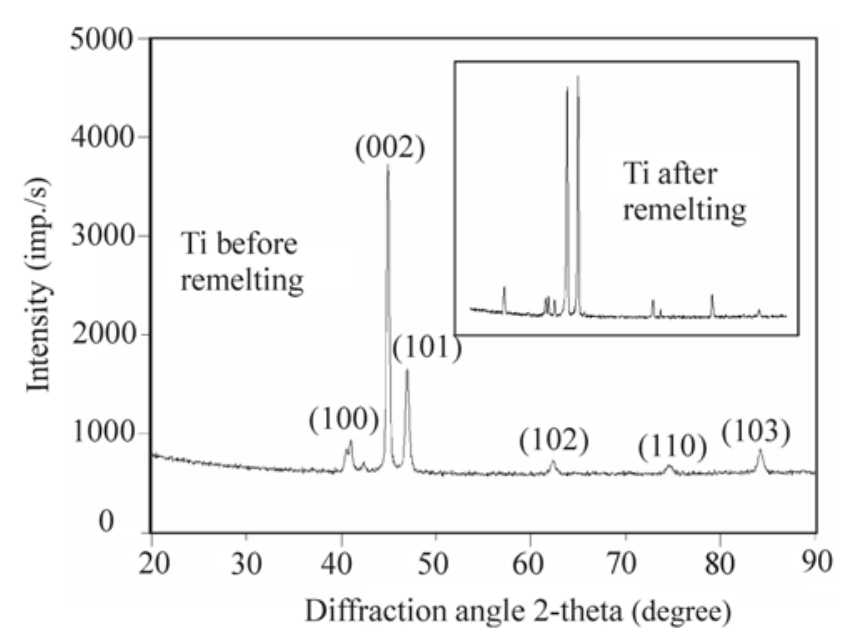

Fig. 8. Diffraction patterns of non-remelted and lasertreated titanium.

laser treatment revealed the presence of oxygen both on the surface of the melted band and in the lasermodified zone. The highest oxygen content was found on the surface of the remelted bands. The EDS investigations of the remelted band surface also revealed the presence of Si and C impurities originating from abrasive materials used in the preparation of the samples for metallographic investigations. The EDS studies of the micro-areas located in three different locations of the remelted zone, i.e. in the subsurface zone, in the central part of the remelted zone and in the lower part of this zone, showed a clear regularity, namely a decrease in oxygen content in the material as it moved away from the surface, until complete disappearance in material core. This dependence was recorded in all the samples subjected to EDS analysis. No nitrogen was found in any of the analysed samples, which is worth emphasizing. The results of the EDS analysis are presented in Table 2 and Fig. 9.

\section{Conclusions}

The following conclusions can be drawn from this study:

1. Surface remelting treatment of CP-Ti using a $\mathrm{CO}_{2}$ laser beam leads to the diffusionless martensitic transformation $\beta \rightarrow \alpha^{\prime}$ and the presence of fine $\alpha^{\prime}$ martensite in the surface layer.

2. Using an s-b-s dual laser beam facilitates the remelting process and provides additional tools that are useful in shaping the treated zone.

3. The dimensions of the treated zone depend on the treatment parameters. The adjusting the treat-
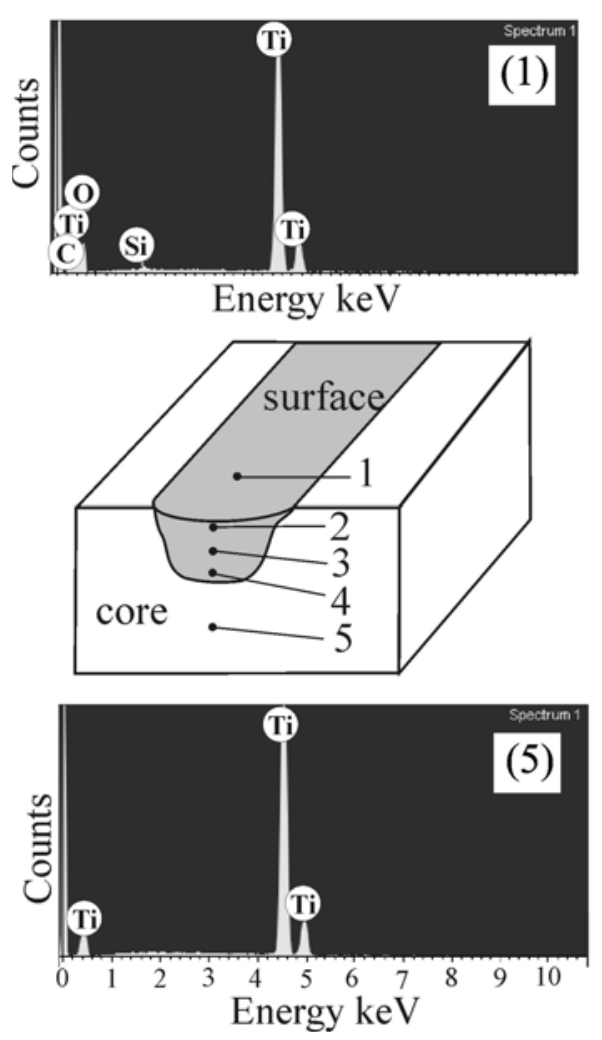

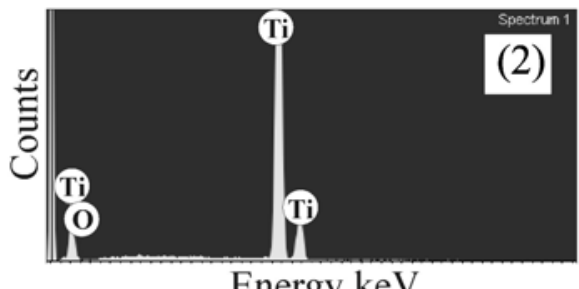

Energy keV

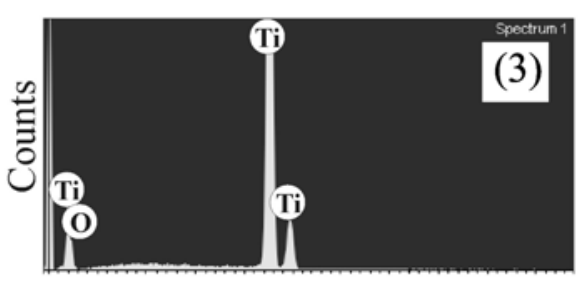

Energy keV

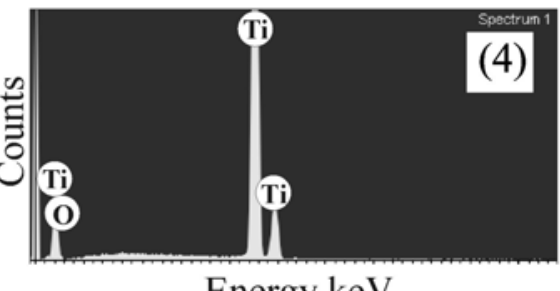

Energy keV

Fig. 9. EDS results of different micro-areas: 1 - surface, 2 - near surface, 3 - central part of the remelted zone, 4 - lower part of the remelted zone, 5 - core. Laser processed Ti sample at laser power $1000 \mathrm{~W}$ and scan rate of $0.5 \mathrm{~m} \mathrm{~min}^{-1}$. 
Table 2. Results of EDS analysis of laser processed Ti sample; treatment parameters: $P=1000 \mathrm{~W}, V_{\mathrm{p}}=0.5 \mathrm{mmin}^{-1}$

\begin{tabular}{|c|c|c|c|c|c|c|c|}
\hline \multirow{3}{*}{\multicolumn{2}{|c|}{ Analysed micro-areas }} & \multicolumn{6}{|c|}{ Atomic and weight share } \\
\hline & & \multicolumn{2}{|c|}{ Titanium } & \multicolumn{2}{|c|}{ Oxygen } & \multicolumn{2}{|c|}{ Contaminations $(\mathrm{Si}, \mathrm{C})$} \\
\hline & & $($ wt.\%) & $($ at. $\%)$ & $(\mathrm{wt} . \%)$ & $($ at. $\%)$ & $($ wt.\%) & $($ at.\%) \\
\hline 1. & Surface & 62.09 & 34.59 & 33.23 & 55.43 & 4.68 & 9.97 \\
\hline 2. & Subsurface zone & 95.68 & 88.10 & 4.32 & 11.90 & - & - \\
\hline 3. & Central part of remelted zone & 97.88 & 93.92 & 2.12 & 6.08 & - & - \\
\hline 4. & Lower part of remelted zone & 98.31 & 95.11 & 1.69 & 4.89 & - & - \\
\hline 5. & Core & 100 & 100 & - & - & - & - \\
\hline
\end{tabular}

ment parameters allows one to modify the dimensions of the material remelting zone, i.e. the depth and width of that zone. Increasing the laser power or reducing the scanning speed leads to an increase in the dimensions of the remelted zone.

4. Titanium shows high reactivity at increased temperatures. Hence the remelting treatment of titanium requires special care to protect the melted material against the influence of the ambient atmosphere.

5. Laser surface treatment is an effective and promising solution, making it possible to induce beneficial changes in the microstructure of titanium.

\section{References}

[1] Cui, Ch., Hu, B.-M., Zhao, L., Liu, S.: Mater. Des., 32, 2011, p. 1684. doi:10.1016/i.matdes.2010.09.011

[2] Makuch, N., Kulka, M., Dziarski, P., Przestacki, D.: Opt. Lasers Eng., 57, 2014, p. 64. doi:10.1016/i.optlaseng.2014.01.019

[3] Wang, Y., Li, C., Tian, W., Yang, Y.: Appl. Sur. Sci., 255, 2009, p. 8603. doi:10.1016/i.apsusc.2009.06.033

[4] Hamad, A. R., Abboud, J. H., Shuaeib, F., Benyounis, K. Y.: Adv. Eng. Software, 41, 2010, p. 674. doi:10.1016/j.advengsoft.2009.10.010

[5] Luo, Y., Ge, S., Liu, H., Jin, Z. J.: Biomech., 42, 2009, p. 2708. doi:10.1016/i.jbiomech.2009.08.003

[6] Trtica, M., Gakovic, B., Batani, D., Desai, T., Panjan, P., Radak, B.: Appl. Surf. Sci., 253, 2006, p. 2551. doi:10.1016/j.apsusc.2006.05.024

[7] Poulon-Quintina, A., Watanabe, I., Watanabe, E., Bertranda, C.: Dental Mater., 28, 2012, p. 945. doi:10.1016/j.dental.2012.04.008

[8] Momin, O., Shuja, S. Z., Yilbas, B. S.: Int. J. Thermal Sci., 54, 2012, p. 230. doi:10.1016/i.ijthermalsci.2011.12.003

[9] Ciganovic, J., Stasic, J., Gakovic, B., Momcilovic, M., Milovanovic, D., Bokorov, M., Trtica, M.: Appl. Surf. Sci., 258, 2012, p. 2741. doi:10.1016/j.apsusc.2011.10.125

[10] Kwok, C. T., Cheng, F. T., Man, H. C.: Surf. Coat. Technol., 202, 2007, p. 336. doi:10.1016/i.surfcoat.2007.05.085
[11] Iwaszko, J., Kudła, K.: Bull. Pol. Ac.: Tech. Sci., 64, 2016, p. 937. doi:10.1515/bpasts-2016-0102

[12] Chikarakaraa, E., Naherb, S., Brabazon, D.: Appl. Surf. Sci., 302, 2014, p. 318. doi:10.1016/j.apsusc.2013.10.099

[13] Matejicek, J., Holub, P.: J. Thermal Spray Technol., 23, 2014, p. 750. doi:10.1007/s11666-014-0067-4

[14] Iwaszko, J., Strzelecka, M.: Opt. Lasers Eng., 81, 2016, p. 63. doi:10.1016/j.optlaseng.2016.01.009

[15] Balla, V. K., Dey, S., Muthuchamy, A. A., Janakiram, G. D., Das, M., Bandyopadhyay, A.: J. Biomed. Mater. Res. Part B, 106, 2018, p. 569. doi:10.1002/jbm.b.33872

[16] Sun, Z., Annergren, I., Pan, D., Mai, T. A.: Mater. Sci. Eng. A, 345, 2003, p. 293. doi:10.1016/S0921-5093(02)00477-X

[17] Nishio, K., Yamaguchi, T., Era, H., Katoh, M.: Mater. Trans., 45, 2004, p. 1613. doi:10.2320/matertrans.45.1613

[18] Watanabe, I., McBride, M., Newton, P., Kurtz, K. S.: Dental Mater., 25, 2009, p. 629. doi:10.1016/j.dental.2008.11.006

[19] Huang, C., Tu, J., Wen, Y.-R., Hu, Z., Zhou, Z.M., Dong, A.-P., Zhu, G.-L.: Acta Metall. Sin. (Engl. Lett.), 31, 2018, p. 321. doi:10.1007/s40195-017-0608-1

[20] Gammon, L. M., Briggs, R. D., Packard, J. M., Batson, K. W., Boyer, R., Domby, C. W.: Metallography and Microstructures of Titanium and Its Alloys. ASM Handbook. Volume 9. Metallography and Microstructures. Materials Park, ASM International 2004. doi:10.1361/asmhba0003779

[21] Attar, H., Ehtemam-Haghighi, S., Kent, D., Wu, X., Dargusch, M. S.: Mater. Sci. Eng. A, 705, 2017, p. 385. doi:10.1016/j.msea.2017.08.103

[22] Oh, M. S., Lee, J-Y., Park, J. K.: Metall. Mater. Trans. A 35, 2004, p. 3071. doi:10.1007/s11661-004-0052-5

[23] Yang, J., Yu, H., Yin, J., Gao, M., Wang, Z. Zeng, X.: Mater. Des., 108, 2016, p. 308. doi:10.1016/j.matdes.2016.06.117

[24] Gu, D., Hagedorn, Y-C., Meiners, W., Meng, G., Batista, R. J. S., Wissenbach, K., Poprawe, R.: Acta Mater., 60, 2012, p. 3849. doi:10.1016/j.actamat.2012.04.006 